\title{
Closely related Drosophila melanogaster strains with altered fitness also show changes in their hobo element properties
}

\author{
VN Bolshakov ${ }^{1}$, AP Galkin ${ }^{2}$, LZ Kaidanov ${ }^{2}$, \\ VA Gvozdev ${ }^{3}$, C Louis ${ }^{1 *, 4}$ \\ 1 Institute of Molecular Biology and Biotechnology, FORTH, PO Box 1527, \\ 711.10 Heraklion, Crete, Greece; \\ 2 Saint Petersburg State University, Department of Genetics, Saint Petersburg, Russia; \\ ${ }^{3}$ Russian Academy of Sciences, Institute of Molecular Genetics, Moscow, Russia; \\ 4 University of Crete, Department of Biology, Heraklion, Crete, Greece
}

(Received 4 August 1993; accepted 5 January 1994)

Summary - A set of Drosophila melanogaster strains of common origin, but with different fitness characteristics, established either spontaneously or after selection for the specific fitness parameters, appear to induce non-P-element-mediated gonadal atrophy in appropriate crosses to tester strains containing or lacking hobo elements $(\mathrm{H}$ and $\mathrm{E}$ strains). Using the gonadal dystrophy (GD) sterility assay, as well as genomic Southern blot hybridization and in situ hybridization on polytene chromosomes, it was found that all these strains possess hobo elements whose dysgenic activity, composition, copy number and cytogenetic locations appeared to be variable. In general, low fitness strains have moderate hobo-activity and hobo-repression potentials, while high fitness strains show no hobo-activity but also quite high hobo-repression potentials. Although distinct differences in the composition, copy number and location of the hobo elements in the genome were observed between these 2 groups of strains, these variations did not show any profound correlation with either hobo-related dysgenic potential or the fitness of the strains.

Drosophila melanogaster / selection / fitness / transposable element / hobo

Résumé - Des souches étroitement apparentées de Drosophila melanogaster avec des aptitudes reproductives modifiées manifestent aussi des changements dans les propriétés de leurs éléments hobo. Différentes lignées de Drosophila melanogaster, issues d'une population naturelle russe, ont été sélectionnées sur des caractéristiques de fitness. Ces lignées, comme les lignées témoins, présentent des activités dysgéniques variables non reliées à l'élément transposable $P$. Nous montrons que la stérilité GD (gonadal dystrophy) qu'elles induisent est due à l'élément hobo et, de plus, que ces lignées ont des potentiels

* Correspondence and reprints 
dysgéniques différents. Les analyses moléculaires réalisées par buvardage de Southern et par hybridation in situ sur les chromosomes polytènes font apparaître que ces lignées possèdent un nombre variable d'éléments hobo, qui ont des structures et des localisations cytogénétiques différentes. En général, les lignées ayant une fitness basse présentent une activité hobo et un potentiel de répression modérés, alors que les lignées ayant une fitness plus forte n'ont pas d'activité hobo, mais un potentiel de répression assez élevé. Bien que ces 2 groupes diffèrent par la structure, le nombre et la localisation cytogénétique de leurs éléments hobo, les différences mises en évidence ne montrent pas de corrélation directe, que ce soit avec le potentiel dysgénique ou avec la fitness des lignées analysées. Une relation entre les sélections réalisées pour établir les lignées et l'évolution de leurs éléments hobo est discutée.

Drosophila melanogaster / sélection / fitness / élément transposable / hobo

\section{INTRODUCTION}

The evaluation of the genetic consequences of selection is one of the key purposes of population genetics, especially in the context of the theory of breeding (Hill and Caballero, 1992). To address this problem, a set of Drosophila melanogaster strains, originating from a natural population from Yessentuki (Russia), was established after close inbreeding and long-term selection for differences in male mating activity. Selection for low male mating activity also led to correlated changes in a number of morphological, physiological, behavioural, biochemical and genetic features which, altogether, greatly reduced the overall fitness of these strains, and thus made it possible to characterize them as low fitness or high fitness strains (reviewed in Kaidanov, 1980, 1990).

In spite of the close inbreeding, these strains appeared to possess a significant genetic load and a high rate of spontaneous mutability, including the occurrence of chromosomal rearrangements (Kaidanov, 1980, 1990; Kaidanov et al, 1991). Experiments directed to investigate the sources of this genetic instability showed that in the course of isogenization of the strains' 2 nd chromosomes in order to evaluate their genetic loads and the rates of spontaneous mutability, the female progeny exhibited a high rate of gonadal dystrophy (GD). In these crosses, males from one of the low fitness strains, $L A$, were crossed with the females of a laboratory strain containing a balancer for the 2nd chromosome. This finding was highly reminiscent of hybrid dysgenesis, a syndrome attributed to the activation of the transposable elements $P$ or hobo (Louis and Yannopoulos, 1988; Blackman and Gelbart, 1989; Engels, 1989). Since it was known that $L A$ does not contain any $P$ elements in its genome (Pasyukova et al, 1987), the probability that hobo elements were responsible for the GD sterility detected was checked by crosses to appropriate tester strains, containing or lacking hobo elements. These experiments revealed the presence of active hobo elements in LA (Kaidanov et al, 1991) thus raising the possibility that hobo may be the causative factor for the genetic instability observed. We extended our analysis to several strains which, though related, exhibited different fitness characteristics. Here, we report results on composition, copy number, cytogenetic location and dysgenic properties of their hobo elements. 


\section{MATERIALS AND METHODS}

The following $D$ melanogaster strains (kept on standard corn-meal food at $25^{\circ} \mathrm{C}$ ) were used for experiments:

$L A$ : low activity strain, obtained from a natural population in Yessentuki (Russia) in 1965 as a result of inbreeding and long-term selection for low male mating activity. By the time of the beginning of the experiments described here, it had passed $\sim 600$ generations of selection.

$H A$ and $L A^{+}$: high activity strains, obtained independently from $L A$ at its 70 th and 163rd generation of maintenance, respectively, by selection for high male mating activity and close inbreeding. These 3 strains ( $L A, H A$ and $\left.L A^{+}\right)$were kept in the collection as families obtained from individual brother-sister matings and were described in detail by Kaidanov (1980, 1990).

$L A 6^{-}$and $L A 6^{+}$: low activity and high activity strains, respectively, selected by close inbreeding from a high fitness strain $(L A 6)$ that arose spontaneously from one of the families of $L A$, and was subsequently lost from the collection. After the initial selection and close inbreeding, $L A G^{-}$and $L A G^{+}$are kept in the collection by mass mating without further selection.

LApas: low activity strain, established from one of the families of $L A$ and reared by mass mating without further selection.

23.5MRF/CyL $L^{4}$ : a strain containing active $\mathrm{P}$ and hobo elements (PH-strain) and capable of weak induction of $\mathrm{P}-\mathrm{M}$ hybrid dysgenesis and strong induction of $\mathrm{H}-\mathrm{E}$ hybrid dysgenesis (Yannopoulos et al, 1987; Stamatis et al, 1989).

$C y L / P m$ : an $\mathrm{ME}$ strain containing a 2nd chromosome balancer and unable to suppress $\mathrm{H}-\mathrm{E}$ hybrid dysgenesis. Female progeny resulting from crosses between this strain's females to 23.5MRF/Cy $L^{4}$ males exhibit high levels of gonadal atrophy (Kaidanov et al, 1991).

The test for male mating activity was performed as described by Kaidanov (1980, 1990). Single mature males from the strain to be tested were put in the same vial with 2-3 virgin-wild type females and the process of copulation was observed. Male mating activity was determined as the percentage of males succeeding in copulating with virgin females within $30 \mathrm{~min}$. For each strain, 55-90 males were tested.

The GD sterility assay was performed according to the conditions described by Yannopoulos (1978). To determine the hobo-activity potential, the males of the strain under investigation were crossed with the $C y L / P m$ tester females, while to determine the hobo-repression potential, the females of the strain were crossed with 23.5MRF/CyL $L^{4}$ males. As a control, the GD sterility assay was also performed both within-strain and for the reciprocal crosses. All crosses were performed at $25^{\circ} \mathrm{C}$ to maximize the manifestation of H-E hybrid dysgenesis (Stamatis et al, 1989). Female progeny were collected every day and transferred to fresh vials for $3-4 \mathrm{~d}$ for maturation of the gonads, which were then dissected to analyze their morphology. The induction of GD-sterility was measured as the frequency of atrophic gonads. For each strain, 1-4 replicates of each cross were performed and 50-500 females were scored.

Genomic DNA for Southern-blot hybridization was extracted from 200 flies/ strain as described by Ashburner (1989). Approximately $2 \mu \mathrm{g}$ DNA was digested with $X$ ho I restriction endonuclease, separated electrophoretically in $1.2 \%$ agarose 
gels and blotted onto nylon membrane filters following standard protocols (Sambrook et al, 1989). Hybridization was performed according to Church and Gilbert (1984) using as a probe ${ }^{32}$ P-labelled plasmid pHFL1 which contains a complete hobo element (Blackman et al, 1989).

In situ hybridization to salivary gland polytene chromosomes was performed as described by Ashburner (1989), using biotin-labelled plasmid pHcSac, containing a complete hobo element as a probe (Stamatis et al, 1989).

The $t$-test (Sokal and Rohlf, 1969) was used to compare the means in our experiments.

\section{RESULTS}

\section{Male mating activity}

As some of the strains under investigation are kept without any further selection with respect to their male mating activity, we first performed a series of tests for all $L A$ derivatives analyzed here. The data on their male mating activity are presented in table I. They confirm the status of $L A$ and LApas as low activity strains (no matings within the first $30 \mathrm{~min}$ ). The remaining strains showed a gradual increase in male mating activity, from 25.0 and $52.0 \%$ for the more recently established strains $L A 6^{-}$and $L A 6^{+}$to 76.6 and $94.0 \%$ for $H A$ and $L A^{+}$which had been established earlier.

Table I. Male mating activity, expressed as the percentage of successfully copulating males, GD sterility, expressed as the percentage of atrophic gonads in the females of the strain, and hobo activity and hobo repression potentials expressed as the percentage of atrophic gonads in the female progeny of test crosses using the strains under investigation*

\begin{tabular}{|c|c|c|c|c|c|c|}
\hline \multirow[t]{2}{*}{ Strain } & \multirow[t]{2}{*}{$\begin{array}{l}\text { Male mating } \\
\text { activity }\end{array}$} & \multirow[t]{2}{*}{$\begin{array}{l}\text { Intrastrain } \\
G D \text { sterility }\end{array}$} & \multicolumn{2}{|c|}{$\begin{array}{l}\text { hobo-activity } \\
\text { potential }\end{array}$} & \multicolumn{2}{|c|}{$\begin{array}{l}\text { hobo-repression } \\
\text { potential }\end{array}$} \\
\hline & & & Test cross & Control & Test cross & Control \\
\hline $\begin{array}{l}\text { LA } \\
\text { LApas }\end{array}$ & $\begin{array}{l}0 \\
0\end{array}$ & $\begin{array}{r}12.2 \pm 3.8 \\
1.4 \pm 1.4\end{array}$ & $\begin{array}{l}32.6 \pm 2.6 \\
36.5 \pm 4.5\end{array}$ & $\begin{array}{l}0 \\
0\end{array}$ & $\begin{array}{l}47.2 \pm 2.2 \\
38.0 \pm 3.5\end{array}$ & $\begin{array}{l}0.4 \pm 0.4 \\
1.4 \pm 1.4\end{array}$ \\
\hline $\begin{array}{l}L A 6^{-} \\
L A 6^{+}\end{array}$ & $\begin{array}{l}25.0 \pm 5.6 \\
52.0 \pm 6.4\end{array}$ & $\begin{array}{l}0.6 \pm 0.9 \\
0\end{array}$ & $\begin{array}{l}0.7 \pm 0.5 \\
0.8 \pm 0.6\end{array}$ & $\begin{array}{l}0 \\
1.6 \pm 1.8\end{array}$ & $\begin{array}{l}25.0 \pm 5.3 \\
23.0 \pm 5.9\end{array}$ & $\begin{array}{l}0 \\
0\end{array}$ \\
\hline $\begin{array}{l}H A \\
L A^{+}\end{array}$ & $\begin{array}{l}76.6 \pm 4.5 \\
94.0 \pm 2.4\end{array}$ & $\begin{array}{l}0 \\
2.5 \pm 1.3\end{array}$ & $\begin{array}{l}0 \\
0\end{array}$ & $\begin{array}{l}0 \\
0\end{array}$ & $\begin{array}{l}14.0 \pm 2.1 \\
19.8 \pm 2.3\end{array}$ & $\begin{array}{l}0 \\
1.2 \pm 0.8\end{array}$ \\
\hline
\end{tabular}

* The mean value and its standard error are given. The 'control' columns refer to the respective reciprocal crosses. For description of test and control crosses, as well as the GD sterility assay, see Materials and methods.

\section{Activity and repression abilities of hobo elements}

As the strains under investigation were previously shown not to contain any $\mathrm{P}$ elements (Pasyukova et al, 1987), we concentrated our analysis on the study of 
hobo-mediated genetic instability. The hobo-activity potential of the strains was determined by the GD sterility assay using the females from the E strain $C y L / P m$ as tester strains, a high percentage of dystrophic gonads in the progeny of these crosses being indicative of a higher hobo-mediated dysgenic induction. The hoborepression potential was determined in a similar way, this time crossing females from the $L A$ derivatives with males of the $\mathrm{H}$-strain $23.5 M R F / C y L^{4}$. In this case, the higher the proportion of atrophic gonads among female progeny, the lower the potential of the strain under investigation to repress the action of hobo. In a test cross of $C y L / P m$ females to $23 . M R F / C y L^{4}$ males, the GD sterility among 150 female progeny reached $90 \%$, confirming that the latter still retained its strong hobo-activity potential. As a control, intrastrain GD sterility assays were performed and, with the only exception of $L A$, where intrastrain sterility reached a moderate rate of about $12 \%$, the proportion of atrophic gondas in all other strains did not exceed the background levels $(0-2.5 \%$, table I).

For both experiments, in control reciprocal crosses, the proportion of atrophic gonads was very low if any $(0-1.6 \%$, table I), thus implying that the hobo elements are the most probable causative factors of the GD sterility in experimental crosses. The data presented in table I show that low activity strains $L A$ and $L A p a s$ appeared to have similar moderate hobo-activity potential ( 32.6 and $36.5 \%$ of atrophic gonads, respectively; $t=0.66, p>0.05$ ), while the intermediate strains $L A 6^{-}$and $L A 6^{+}$ and the high activity strains $H A$ and $L A^{+}$apparently lost their induction potential sometime after their establishment (GD sterility $=0-0.8 \%$ ). The hobo-repression potential was lowest, though different, for $L A$ and LApas $(47.0$ and $38.0 \%$ of atrophic gonads, respectively; $t=2.18, p<0.05)$. Strains $L A 6^{-}$and $L A 6^{+}$showed similar hobo-repression potentials (GD sterility $=25.0$ and $23.0 \%$, respectively; $t=0.25, p>0.05)$, which were significantly higher than that of LApas $(t=2.06$, $p<0.05$ and $t=2.19, p<0.05$, respectively). The strongest hobo-repression potentials were observed in $L A^{+}$and $H A$ (19.8 and $14.0 \%$ of atrophic gonads, respectively; $t=1.63, p>0.05$ ), values that are not significantly different from that observed for $L A 6^{+}(t=0.63, p>0.05$ and $t=1.44, p>0.05$, respectively).

\section{Composition of hobo elements}

Genomic DNAs of the strains were digested with Xho I restriction endonuclease, which has recognition sites close to both ends of the complete hobo element, yielding a characteristic fragment of $2.6 \mathrm{~kb}$ after Southern-blot hybridization with a hobo probe. In addition, Xho I digests also produce fragments of smaller molecular weight, corresponding to different internal deletion derivatives of hobo (Streck et al, 1986). As a control, 23.5MRF/CyL $L^{4}$ flies were also analyzed (fig 1A), showing their characteristic pattern of hybridization (Stamatis et al, 1989), while as expected, no hybridization corresponding to either complete or deleted hobo elements was seen in the corresponding digests of the $C y L / P m$ strain (fig 1A), confirming that it is a bona fide $\mathrm{E}$ strain (Kaidanov et al, 1991).

All tested $L A$ derivatives appeared to possess the $2.6 \mathrm{~kb}$ fragment indicating the presence of full-length hobo elements in their genome. On the other hand, the pattern of hobo-deletion derivatives was qualitatively and quantitatively different for all strains (fig 1B). In $L A$, the most intense band has a length of $1.7 \mathrm{~kb}$ with some weaker bands also being present, while the predominant band in LApas is 


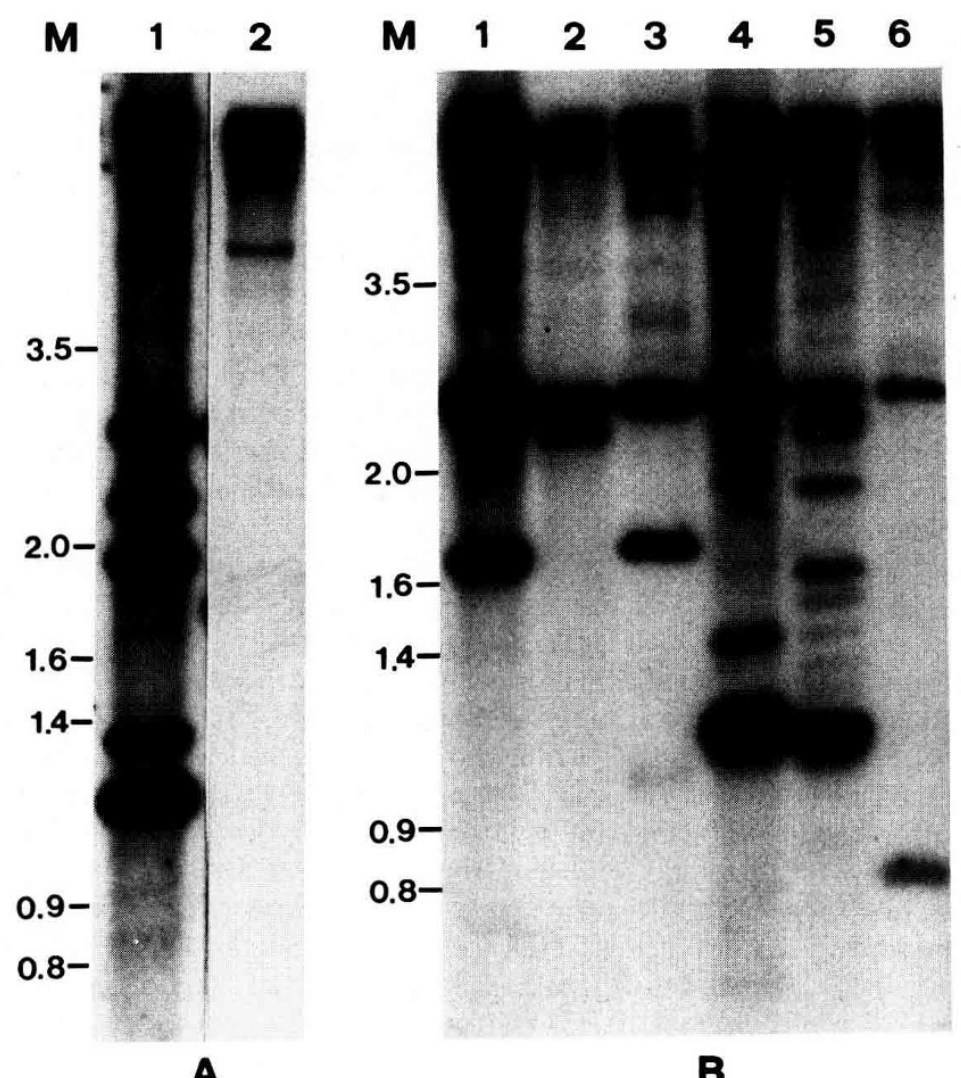

Fig 1. Southern-blot analysis of Xho I-digested genomic DNAs isolated from different strains using $p H F L 1$, a plasmid containing a complete hobo element, as a probe. A: 1 23.5MRF/CyL $L^{4} ; 2-C y L / P m ;$ B: $1-L A ; 2-L A$ pas; $3-L A 6^{-} ; 4-H A ; 5-L A^{+} ; 6-L A 6^{+} ; \mathrm{M}-$ molecular size markers (in $\mathrm{kb}$ ).

$2.2 \mathrm{~kb}$ long. In the $L A 6^{-}$the most prominent band also corresponds to a length of $1.7 \mathrm{~kb}$ and there is a very weak band of $1 \mathrm{~kb}$. The most abundant fragment in the 2 high activity strains ( $H A$ and $L A^{+}$) has a length of $1.15 \mathrm{~kb}$ with an additional intense band of $1.4 \mathrm{~kb}$ appearing in digest of $H A$ as well as numerous weaker bands. Finally, the only intense band observed in $L A \sigma^{+}$is $0.9 \mathrm{~kb}$ long.

\section{hobo elements copy number and their distribution on the polytene chromosomes}

To determine the copy number of the hobo elements and their location in the genome of the strains under investigation we performed an in situ hybridization of a labelled hobo element to polytene chromosomes. Squashes were prepared from salivary glands of several larvae, taken either from one vial for each strain kept by 
mass matings, or from 2 vials (families) for each of the strains kept in families. The copy number of hobo elements and the sites of their cytological location were analysed for each individual larva. The data from this experiment are presented in table II. Both intrastrain and interstrain variation in copy number and their location are characteristic for all strains. In low activity strains $L A$ and $L A$ pas the number of hobo elements were between 12 to 15 and 10 to 22 respectively, while in the intermediate activity strains $L A 6^{-}$and $L A \sigma^{+}$they were from 8 to 11 and from 13 to 15 , respectively. Both high activity strains, $H A$ and $L A^{+}$, showed a considerably higher copy number (40-42 and 36-37, respectively).

The proportion of polymorphic sites (expressed as the ratio of the number of sites varying among individuals from one strain, to the total number of sites revealed within the same strain) also appeared to be different between the strains (table II). Quite low polymorphism was observed in strains kept as individual families with selection. $H A$ had $12 \%$ polymorphic sites, the corresponding number for $L^{+}$was $24 \%$, and a higher value $(47 \%)$ was observed for $L A^{-}$. On the other hand, the strains kept by mass matings without selection ( $L A$ pas, $L A 6^{-}$and $L A 6^{+}$) had even higher values $(69,56$ and $63 \%$ of polymorphic sites, respectively).

Analysis of cytological locations of hobo elements revealed that, in the course of selection and subsequent maintenance of the strains, their hobo elements underwent massive transpositions. Only $L A$ and $L A$ pas share 9 common sites among a total of 46 sites for both strains (or 20\%), while all other pair-wise comparisons revealed only 2-5 common sites among a total of 33-84 sites, or 3-12\% (table III). Another strain with decreased activity, $L A 6^{-}$, shared only $2(6.5 \%)$ and $4(8.9 \%)$ sites with $L A$ and $L A p a s$, respectively. Only 2 sites at $17 \mathrm{E}$ and $96 \mathrm{E}$ were common to all 3 . The high activity strains $H A, L A^{+}$, and $L A 6^{+}$had $2-5$ sites in common (3.0-7.7\%), and there were no sites that were shared by all 3 . The most frequent sites among all strains analyzed were $17 \mathrm{~A}, 38 \mathrm{C}, 67 \mathrm{~A}$ and $96 \mathrm{E}$.

\section{DISCUSSION}

In a previous paper (Kaidanov et al, 1991) we showed that the $D$ melanogaster strain $L A$, established from a natural population by close inbreeding and selection for low male mating activity, harboured active hobo elements in its genome. We extended this analysis to encompass $L A$-derivative strains with altered male mating activity, and in this report we present evidence that the hobo elements in these strains underwent considerable changes in their dysgenic properties, composition and copy number, accompanied by extensive transpositions.

Both low activity strains, $L A$ and $L A$ pas, preserved dysgenically active hobo elements resulting in similar intermediate hobo-activity and hobo-repression potentials, as revealed by the GD sterility assays. They also appear to possess quite similar copy numbers of hobo elements, and the differences observed in the composition of hobo elements (notably the presence of the prominent band of $1.7 \mathrm{~kb}$ in $L A$ ) and in their locations in the genomes seem to have no direct effect on dysgenic properties of both strains.

In the strains with intermediate $\left(L A 6^{-}\right.$and $\left.L A 6^{+}\right)$and high male mating activity ( $H A$. and $L A^{+}$) we have found the full absence of hobo-activity and a considerable increase of hobo-repression potentials. These changes, especially evident in the 
Table II. The number of hobo elements on polytene chromosome arms, as well as the total number of sites $(n)$, of polymorphic sites ( $n$ PS) and the percentage of polymorphic sites (in parenthesis) is given for several individuals from the 6 strains investigated, as determined by in situ hybridization of a hobo probe.

\begin{tabular}{|c|c|c|c|c|c|c|c|}
\hline Strain & No of larvae & $\mathrm{X}$ & $2 \mathrm{~L}$ & $2 \mathrm{R}$ & $3 \mathrm{~L}$ & $3 \mathrm{R}$ & Total \\
\hline$L A$ & $\begin{array}{c}1 \\
2 \\
3 \\
4 \\
5 \\
n \text { sites } \\
n \text { PS (\%) }\end{array}$ & $\begin{array}{c}6 \\
4 \\
4 \\
4 \\
4 \\
6 \\
3(50)\end{array}$ & $\begin{array}{c}2 \\
1 \\
2 \\
2 \\
2 \\
2 \\
1(50)\end{array}$ & $\begin{array}{c}3 \\
3 \\
2 \\
2 \\
2 \\
5 \\
4(80)\end{array}$ & $\begin{array}{c}1 \\
1 \\
1 \\
1 \\
1 \\
1 \\
0(0)\end{array}$ & $\begin{array}{c}3 \\
3 \\
3 \\
3 \\
3 \\
3 \\
0(0)\end{array}$ & $\begin{array}{c}15 \\
12 \\
12 \\
12 \\
12 \\
17 \\
8(47)\end{array}$ \\
\hline LApas & $\begin{array}{c}1 \\
2 \\
3 \\
4 \\
n \text { sites } \\
n \text { PS (\%) }\end{array}$ & $\begin{array}{c}5 \\
7 \\
4 \\
5 \\
7 \\
3(43)\end{array}$ & $\begin{array}{c}5 \\
3 \\
2 \\
3 \\
5 \\
3(60)\end{array}$ & $\begin{array}{c}1 \\
2 \\
1 \\
1 \\
2 \\
1(50)\end{array}$ & $\begin{array}{c}5 \\
7 \\
1 \\
1 \\
9 \\
8(89)\end{array}$ & $\begin{array}{c}3 \\
3 \\
2 \\
3 \\
6 \\
5(83)\end{array}$ & $\begin{array}{c}19 \\
22 \\
10 \\
13 \\
29 \\
20(69)\end{array}$ \\
\hline$L A 6^{-}$ & $\begin{array}{c}1 \\
2 \\
3 \\
4 \\
5 \\
n \text { sites } \\
n \text { PS (\%) }\end{array}$ & $\begin{array}{c}1 \\
1 \\
1 \\
1 \\
1 \\
2 \\
2(100)\end{array}$ & $\begin{array}{c}3 \\
3 \\
5 \\
5 \\
4 \\
7 \\
4(57)\end{array}$ & $\begin{array}{c}1 \\
1 \\
1 \\
1 \\
1 \\
1 \\
0(0)\end{array}$ & $\begin{array}{c}0 \\
0 \\
0 \\
0 \\
0 \\
0 \\
0(0)\end{array}$ & $\begin{array}{c}4 \\
3 \\
4 \\
4 \\
3 \\
6 \\
3(50)\end{array}$ & $\begin{array}{c}9 \\
8 \\
11 \\
11 \\
9 \\
16 \\
9(56)\end{array}$ \\
\hline$L A 6^{+}$ & $\begin{array}{c}1 \\
2 \\
3 \\
4 \\
5 \\
n \text { sites } \\
n \text { PS (\%) }\end{array}$ & $\begin{array}{c}3 \\
4 \\
4 \\
4 \\
5 \\
7 \\
4(57)\end{array}$ & $\begin{array}{c}1 \\
2 \\
1 \\
1 \\
2 \\
3 \\
2(67)\end{array}$ & $\begin{array}{c}3 \\
1 \\
3 \\
1 \\
2 \\
3 \\
2(67)\end{array}$ & $\begin{array}{c}3 \\
2 \\
3 \\
3 \\
2 \\
4 \\
3(75)\end{array}$ & $\begin{array}{c}4 \\
4 \\
4 \\
6 \\
4 \\
7 \\
4(57)\end{array}$ & $\begin{array}{c}14 \\
13 \\
15 \\
15 \\
15 \\
24 \\
15(63)\end{array}$ \\
\hline$H A$ & $\begin{array}{c}1 \\
2 \\
3 \\
4 \\
n \text { sites } \\
n \text { PS (\%) }\end{array}$ & $\begin{array}{c}8 \\
7 \\
7 \\
8 \\
8 \\
1(13)\end{array}$ & $\begin{array}{c}5 \\
4 \\
4 \\
4 \\
5 \\
2(40)\end{array}$ & $\begin{array}{c}9 \\
9 \\
10 \\
10 \\
10 \\
1(10)\end{array}$ & $\begin{array}{c}9 \\
9 \\
9 \\
9 \\
9 \\
0(0)\end{array}$ & $\begin{array}{c}11 \\
11 \\
10 \\
11 \\
11 \\
1(9)\end{array}$ & $\begin{array}{c}42 \\
40 \\
40 \\
42 \\
43 \\
5(12)\end{array}$ \\
\hline$L A^{+}$ & $\begin{array}{c}1 \\
2 \\
3 \\
n \text { sites } \\
n \text { PS (\%) }\end{array}$ & $\begin{array}{c}4 \\
4 \\
4 \\
4 \\
0(0)\end{array}$ & $\begin{array}{c}7 \\
8 \\
7 \\
8 \\
1(13)\end{array}$ & $\begin{array}{c}6 \\
5 \\
6 \\
6 \\
1(17)\end{array}$ & $\begin{array}{c}8 \\
10 \\
10 \\
12 \\
5(42)\end{array}$ & $\begin{array}{c}11 \\
10 \\
9 \\
11 \\
3(27)\end{array}$ & $\begin{array}{c}36 \\
37 \\
36 \\
41 \\
10(24)\end{array}$ \\
\hline
\end{tabular}

strains $L A 6^{+}, H A$ and $L A^{+}$, were accompanied by a drastic recomposition of hobodeletion derivatives, which appeared to be completely different from the complement of $L A$ and $L A$ pas. Nevertheless, our results do not imply any correlation between the 
Table III. Pair-wise comparison of the cytogenetic localization of hobo elements of the strains under investigation.

\begin{tabular}{|c|c|c|c|c|c|c|}
\hline Strains & LA & LApas & $\mathrm{LA}^{-}$ & $\mathrm{LA} 6^{+}$ & $\mathrm{HA}$ & $\mathrm{LA}^{+}$ \\
\hline Total No of sites & 17 & 29 & 16 & 24 & 43 & 41 \\
\hline \multirow[t]{2}{*}{$L A$} & & $9(19.5 \%)$ & $2(6.5 \%)$ & $5(12.2 \%)$ & $3(5.0 \%)$ & $4(6.9 \%)$ \\
\hline & & $\begin{array}{l}3 D \quad 6 A 17 A \\
25 F \quad 42 D \\
67 A 85 B \\
96 E 99 A\end{array}$ & $17 A 96 E$ & $\begin{array}{l}10 B 38 C \\
67 A 96 E \\
99 A\end{array}$ & $\begin{array}{l}42 D 57 B \\
96 E\end{array}$ & $\begin{array}{l}17 A 57 B \\
67 A 85 B\end{array}$ \\
\hline \multirow[t]{2}{*}{ LApas } & & & $4(8.9 \%)$ & $4(7.5 \%)$ & $4(5.6 \%)$ & $5(7.1 \%)$ \\
\hline & & & $\begin{array}{l}17 A 38 B \\
38 C 96 E\end{array}$ & $\begin{array}{l}10 A \\
67 A C \\
67 A E\end{array}$ & $\begin{array}{l}7 C 10 A 42 D \\
71 C\end{array}$ & $\begin{array}{l}12 E 17 A \\
67 A 70 C \\
74 A\end{array}$ \\
\hline \multicolumn{7}{|l|}{$L A 6^{-}$} \\
\hline & & & & $2(5.0 \%)$ & $2(3.4 \%)$ & $4(7.0 \%)$ \\
\hline & & & & $38 C 96 E$ & $85 D 91 B$ & $\begin{array}{l}17 A 30 C \\
91 B \text { 92E }\end{array}$ \\
\hline \multicolumn{7}{|l|}{$L A 6^{+}$} \\
\hline & & & & & $2(3.0 \%)$ & $5(7.7 \%)$ \\
\hline & & & & & $10 A 43 D$ & $\begin{array}{l}11 C 64 B \\
67 A 97 C\end{array}$ \\
\hline \multirow[t]{2}{*}{$H A$} & & & & & & $3(3.6 \%)$ \\
\hline & & & & & & $\begin{array}{l}57 A 57 B \\
84 B\end{array}$ \\
\hline$L A^{+}$ & & & & & & - \\
\hline
\end{tabular}

The numbers indicate the sites which are shared by a pair of strains (the percentage is indicated in parentheses) as well as their cytological location in italics.

presence or absence of a deletion derivative and the dysgenic properties and fitness of the strains under investigation. For example, $L A$ and $L A^{-}$have quite similar composition of hobo elements, yet they differ markedly in both characteristics. Similarly, $\mathrm{LA}^{+}$and $\mathrm{LAG}^{+}$have similar dysgenic properties and fitness but exhibit strong differences in the restriction patterns of the hobo elements. More experiments are clearly needed to assess the impact of different members of the hobo element family in the dysgenic properties of a given strain.

While $L A 6^{-}$and $L A 6^{+}$did not differ considerably from $L A$ and $L A p a s$ in terms of the copy number of hobo elements, in $H A$ and $L A^{+}$we observed an amplification of the members of this family. Not unexpectedly, all these processes were accompanied by massive transpositions of hobo elements. Although the in situ hybridization data are limited, we could not detect any specific transpositions of hobo elements that would be coupled to changes in the dysgenic properties or the fitness of the strains. Unlike the case of copia-like elements, which transpose from/to specific sites during 
selection for high and low fitness (Pasyukova et al, 1986), we observed an almost complete reshuffling in the cytological localization of hobo elements. Our data may imply that the process of change in male mating activity of the strains also changed some genetic mechanisms regulating the activity of hobo elements.

In spite of the fact that hobo elements have been studied for almost a decade, little is known about the mechanisms regulating their activity in the genome. Unlike active $\mathrm{P}$ elements, which are fully suppressed by a $\mathrm{P}$ cytotype, and are inactive in the germline and can be mobilized under normal conditions ( $i e$ without considering strains containing engineered $\mathrm{P}$ elements) only in dysgenic crosses (see Engels, 1989), hobo elements can transpose within the strains known to contain active hobo elements without a need for outcrosses (Blackmann et al, 1987; Hatzopoulos et al, 1987; Lim, 1988) and they seem to also be active in somatic cells (Kim and Belyaeva, 1991). The fact that hobo may play a significant role in population biology is also exemplified by the finding that these elements have been found to be located on the breakpoints of naturally occurring inversions (Lyttle and Haymer, 1992). It is not surprising that most of the $D$ melanogaster natural populations, although possessing both complete and deleted hobo elements in their genome, have completely lost the ability to activate them in dysgenic crosses (no hoboactivity potential) while strongly suppressing the activity of foreign hobo elements (high hobo-repression potential) (Pascual and Périquet, 1991). This may imply that some genetic mechanisms develope to suppress the activity of hobo elements and thus prevent deleterious consequences of their transposition (lethal mutations and chromosomal rearrangements). These mechanisms may involve the effects of some specific hobo-deletion derivatives that are wide spread in natural populations (Périquet et al, 1989; 1990) but also other genetic factors, acting in both maternal and zygotic fashion (Ho et al, 1993). Some recent findings also imply that these mechanisms can be flexible, as the hobo-activity and hobo-repression potentials in natural populations can vary seasonally and change rapidly when wild strains are brought into a laboratory environment (Zabalou et al, 1991).

Considering this, we can assume that the selection for low fitness may have somehow prevented the full development of the mechanisms suppressing the activity of hobo elements, as is the case in $L A$. This would have resulted in the transposition of hobo elements within the strains, revealed as heterogeneity in their locations in the genome of several individuals (as a possible source of genetic variability under the conditions of highly unfavourable direction of selection) and their activation in dysgenic crosses. Selection for the high fitness (or its spontaneous increase) eventually derepressed the formation of genomic mechanisms controlling the hobo elements' activity. The fact that all $L A$-derived strains with increased fitness have completely different composition, copy number and genomic distribution of hobo elements and at the same time exhibit an absence of hobo-activity and increased hobo-repression potentials point to the predominance of these nonhobo-mediated regulatory mechanisms over the element's own contribution. The considerable increase in copy number, classes of deletion derivatives and intrastrain site polymorphism of hobo elements that accompanied the formation of repression mechanisms in $H A$ and $L A^{+}$is, at first glance, unexpected. Some preliminary data indicate that during the initial steps of selection of $L A$ from low to high fitness the activity of its hobo elements increased considerably, as revealed by the GD 
sterility assay (AP Galkin and LZ Kaidanov, unpublished observations). This may have created the diversity in the content of hobo elements observed in the $H A$ and $L A^{+}$strains. Experiments are in progress to monitor the changes in hobo properties during the course of selection of $L A$ from low to high male mating activity and the impact of different chromosomes in this process.

\section{ACKNOWLEDGMENTS}

We are indebted to V Yu Sergienko and OV Iovleva for their technical assistance as well as to $\mathrm{G}$ Yannopoulos for helpful discussions. This work was supported by and EMBO East European Fellowship to VNB, by grants from the Frontiers in Genetics programme of the Russian Academy of Sciences to APG, VAG and LZK and by grants from SCIENCE programme of the European Communities (Sci 0171-C) and the Hellenic Secretariat General for Research and Technology to CL.

\section{REFERENCES}

Ashburner M (1989) Drosophila: A Laboratory Manual. Cold Spring Harbor Laboratory Press, Cold Spring Harbor, New York

Blackman RK, Gelbart WM (1989) The transposable element hobo of Drosophila melanogaster. In: Mobile DNA (DE Berg, MW Howe, eds) American Society for Microbiology, Washington, 523-529

Blackman RK, Grimaila R, Koehler MMD, Gelbart WM (1987) Mobilization of hobo elements residing within the decapentaplegic gene complex: suggestion of a new hybrid dysgenesis system in Drosophila melanogaster. Cell 49, 497-505

Blackman RK, Koehler MMD, Grimaila R, Gelbart WM (1989) Identification of fully functional hobo transposable element and its use for germ-line transformation of Drosophila. EMBO J 8, 211-217

Church GM, Gilbert W (1984) Genome sequencing. Proc Natl Acad Sci USA 81, 1991-1995

Engels WR (1989) P elements in Drosophila melanogaster. In: Mobile DNA (DE Berg, MW Howe, eds) American Society for Microbiology, Washington, 437-484

Hatzopoulos P, Monastirioti M, Yannopoulos G, Louis C (1987) The instability of the TE-like mutation $D p(2 ; 2) G Y L$ of Drosophila melanogaster is intimately associated with the hobo element. EMBO J6, 3091-3096

Hill WG, Caballero A (1992) Artificial selection experiments. Ann Rev Ecol Syst 23, 287-310

Ho YT, Weber SM, Lim JK (1993) Interacting hobo transposons in an inbred strain and interaction regulation in hybrids of Drosophila melanogaster. Genetics 134, 895908

Kaidanov LZ (1980) The analysis of genetic consequences of selection and inbreeding in Drosophila melanogaster. Genetica 52/53, 165-181

Kaidanov LZ (1990) The rules of genetical alterations in Drosophila melanogaster inbred lines determined by selection. Arh Biol Nauka (Beograd) 42, 131-148

Kaidanov LZ, Bolshakov VN, Tzygvintzev PN, Gvozdev VA (1991) The sources of genetic variability in highly inbred long-term selected strains of Drosophila melanogaster. Genetica 85, 73-78 
Kim AT, Belyaeva ES (1991) Transposition of mobile elements gypsy (mdg4) and hobo in germ-line and somatic cells of genetically unstable mutator strain of Drosophila melanogaster. Mol Gen Genet 229, 437-444

Lim JK (1988) Intrachromosomal rearrangements mediated by hobo transposons in Drosophila melanogaster. Proc Natl Acad Sci USA 85, 9153-9157

Louis C, Yannopoulos G (1988) The transposable elements involved in hybrid dysgenesis in Drosophila melanogaster. Oxford Surv Eucar Genes 5, 205-250

Lyttle TW, Haymer DS (1992) The role of the transposable element hobo in the origin of endemic inversions in wild populations of Drosophila melanogaster. Genetica 86, 113-128

Pascual L, Périquet G (1991) Distribution of hobo transposable elements in natural populations of Drosophila melanogaster. Mol Biol Evol 8, 282-296

Pasyukova EG, Belyaeva ESp, Ilyinskaya LE, Gvozdev VA (1987) Transposition of mobile dispersed genes $(m d g)$ detected in mixed Drosophila melanogaster genomes carrying combinations of chromosomal pairs originated from different stocks. Genetika (Russ) 23, 605-615

Pasyukova EG, Belyaeva ESp, Kogan GL, Kaidanov LZ, Gvozdev VA (1986) Concerted transpositions of mobile genetic elements coupled with fitness changes in Drosophila melanogaster. Mol Biol Evol 3, 299-312

Périquet G, Hamelin MH, Bigot Y, Hu K (1989) Presence of deleted hobo element Th in Eurasian populations of Drosophila melanogaster. Genet Sel Evol 21, 107-111 Périquet G, Hamelin MH, Kalmes R, Eeken J (1990) Hobo elements and their deletion derivative sequences in Drosophila melanogaster and their sibling species D simulans, D mauritiana and D sechellia. Genet Sel Evol 22, 399-402

Sambrook J, Fritch EF, Maniatis T (1989) Molecular Cloning. A Laboratory Manual. Cold Spring Harbor Laboratory Press, Cold Spring Harbor, New York Sokal RR, Rohlf FJ (1969) Biometry. WH Freeman and Co, San Francisco

Stamatis N, Monastirioti M, Yannopoulos G, Louis C (1989) The P-M and 23.5MRF (hobo) systems of hybrid dysgenesis in Drosophila melanogaster are independent of each other. Genetics 123, 379-387

Streck RD, MacGaffey JE, Beckendorf SK (1986) The structure of hobo transposable elements and their insertion sites. EMBO J 5, 3615-3623

Yannopoulos G (1978) Studies on the sterility induced by the male recombination factor 31.1MRF in Drosophila melanogaster. Genet Res Camb 32, 239-247

Yannopoulos G, Stamatis N, Monastirioti M, Hatzopoulos P, Louis C (1987) hobo is responsible for the induction of hybrid dysgenesis by strains of Drosophila melanogaster bearing the male recombination factor 23.5MRF. Cell 49, 487-495 Zabalou S, Alahiotis S, Yannopoulos G (1991) Seasonal analysis of 23.5MRF (hobo) and P-M hybrid dysgenesis determinants in the Greek natural populations of Drosophila melanogaster. Hereditas 114, 1-13 